\title{
Gallium-Containing Mesoporous Silica: Supported Catalysts with High Catalytic Activity for Oxidation of Benzene, Toluene and $o$-Xylene
}

\author{
Anderson Joel Schwanke, ${ }^{a}$ Sibele B. C. Pergher, ${ }^{a}$ Luiz F. D. Probst ${ }^{b}$ and Rosana Balzer ${ }^{*}, c$ \\ ${ }^{a}$ Programa de Pós Graduação em Ciência e Engenharia de Materiais, UFRN, 59078-970 Natal-RN, Brazil \\ ${ }^{b}$ Departamento de Química, UFSC, 88040-900 Florianópolis-SC, Brazil \\ ${ }^{c}$ Departamento de Engenharias e Exatas, UFPR, 85950-000 Palotina-PR, Brazil
}

\begin{abstract}
Benzene, toluene and xylene (BTX) are a particular class of volatile organic compounds, which are highly toxic pollutants. In this study, samples of gallium-containing mesoporous silica (MS-Ga7\% and MS-Ga11\%) were synthesized and their catalytic activity in the oxidation of BTX was investigated. The physicochemical characterization shows that the inclusion of gallium in the mesoporous silica structure leads to an increase in the number of oxygen vacancies in the structure of the MS-Ga system, which can result in an increase in the total and surface oxygen mobility. The results show the highest conversion for benzene (65\%), with $>40 \%$ for toluene and $>28 \%$ for $o$-xylene. The high catalytic activity observed was attributed to a combination of several factors including a higher number of active sites (gallium and gallium oxide) being exposed, with a greater mobility of the active oxygen species on the surface of the catalyst promoting the catalytic activity.
\end{abstract}

Keywords: gallium, mesoporous silica, catalytic oxidation, BTX

\section{Introduction}

The emission of high levels of volatile organic compounds (VOC) to the atmosphere during various industrial and commercial processes is considered detrimental to human health and the environment. ${ }^{1-6}$ Benzene, toluene and xylene (BTX) are volatile organic compounds used as common solvents as well as raw materials in the production of other chemicals. ${ }^{7-9}$ All three substances are known to be toxic. ${ }^{10,11}$ Several VOC removal technologies, such as flame combustion, catalytic combustion, catalytic destruction using ozone and plasma, photocatalytic decomposition, adsorption processes and biological treatment, have been developed to eliminate VOCs. ${ }^{2,6,12-14}$ Catalytic oxidation is considered to be the most effective approach, mainly due to its high efficiency in the degradation to carbon dioxide and water, even in effluents with low concentrations of VOCs, and low energy cost. ${ }^{3,15}$ However, it is extremely difficult to achieve the complete combustion of VOCs at low temperatures. Thus, it is important to develop a novel active catalyst which can promote complete oxidation at the lowest possible temperatures. Conventional catalysts are supported on inorganic materials such as alumina and other metal oxides.

*e-mail: rosanabalzer@gmail.com
However, the success of the catalyst is dependent on the nature of the support used. Common catalyst supports include activated carbons, silica, alumina, polymers and zeolites. Mesoporous silicas (MSs), for instance MCM-41, have been shown to be suitable supports for catalysts. ${ }^{16,17}$ These mesoporous materials possess some important properties for catalytic purposes, such as high specific surface area, large pore volume and highly ordered pore structures with narrow pore size distributions, which are dependent on the synthesis chemicals and conditions..$^{18,19}$ The synthesis of these materials requires a source of silica, usually commercial, a structure directing agent, a solvent, a mineralizer agent, and these materials have been extensively investigated as promising catalyst supports. Thus, the aim of this study was to synthesize a galliumcontaining mesoporous silica (type MCM-41) catalyst with surface acidity, which can provide high catalytic efficiency for the complete oxidation of BTX without the formation of reaction by-products other than carbon dioxide and water.

\section{Experimental}

Catalyst preparation and characterization

For the synthesis of gallium-containing mesoporous silica, hexadecyltrimethylammonium bromide (CTABr, 
Sigma-Aldrich) was added to deionized water until its dissolution. In the next step, $25 \%$ of tetramethylammonium hydroxide (TMAOH, Sigma-Aldrich) and Aerosil 200 silica $\left(\mathrm{SiO}_{2}\right.$, Degussa) was added to the solution and the mixture was stirred for $1 \mathrm{~h}$. On the resulting gel-synthesis (molar composition $1 \mathrm{SiO}_{2}: 0.2 \mathrm{TMAOH}: 0.1 \mathrm{CTABr}: 20 \mathrm{H}_{2}$ ), gallium nitrate $\left(\mathrm{Ga}\left(\mathrm{NO}_{3}\right)_{3}\right.$, Sigma-Aldrich) was added to generate 5 and $10 \mathrm{wt} . \%$ of gallium oxide on the total weight of silica. The resulting gel was transferred to stainless autoclaves with Teflon interior and placed in an oven at $135^{\circ} \mathrm{C}$ for $24 \mathrm{~h}$. The materials were filtered with distilled water $(\mathrm{pH}=7)$, dried in an oven for $12 \mathrm{~h}$ at $60{ }^{\circ} \mathrm{C}$ and calcined at $540{ }^{\circ} \mathrm{C}$ in a nitrogen flow $\left(5^{\circ} \mathrm{C} \mathrm{min}^{-1}\right.$ range) and synthetic air for $12 \mathrm{~h}$. The gallium-containing mesoporous silica samples obtained were named MS-Gax, where " $x$ " corresponds to the gallium oxide content determined by X-ray fluorescence (XRF).

The catalysts were analyzed by $\mathrm{X}$-ray powder diffraction (XRD), (Bruker ${ }^{\circledR}$-AXS D2 Phaser) with $\mathrm{Cu}-\mathrm{K} \alpha$ radiation $(\mathrm{V}=30 \mathrm{kV} ; \lambda=1.54 \AA$ ) using a Lynxeye detector. The binding energies of the elements were determined by X-ray photoemission spectroscopy (XPS) (VG Microtech $3000^{\circledR}$ ). The $\mathrm{O}_{2}$-chemisorption measurements were conducted at $600{ }^{\circ} \mathrm{C}$ using a ChemBET analyzer (Quantachrome Instruments ${ }^{\circledR}$ ). Nitrogen adsorption and desorption isotherms at $-196{ }^{\circ} \mathrm{C}$ were obtained using an ASAP 2020 analyzer (Micrometrics ${ }^{\circledR}$ ). The Fourier transform infrared (FTIR) analysis was performed using a Varian ${ }^{\circledR}$ 640-IR spectrometer and the results were obtained with a resolution of $4 \mathrm{~cm}^{-1}$, accumulating 32 scans in the wavelength range of $4000-400 \mathrm{~cm}^{-1}$. The X-ray fluorescence (XRF) analysis was carried out using a Shimadzu ${ }^{\circledR} 720$-EDX solid state detector, type $\mathrm{Si}(\mathrm{Li})$, with a $10 \mathrm{~mm}$ collimator in a vacuum atmosphere. The morphology and microstructure of the catalysts were determined by scanning electron microscopy (SEM, Carl Zeiss ${ }^{\circledR}$, EVO50) and transmission electron

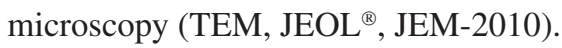

\section{Catalytic activity tests}

The catalytic oxidation of benzene, toluene and $o$-xylene was performed in a fixed bed tubular quartz reactor under atmospheric pressure. The following conditions were used: $0.030 \mathrm{~g}$ catalyst, inlet flows of benzene 1.2 , toluene 0.7 and $o$-xylene $0.5 \mathrm{~g} \mathrm{~m}^{-3}$ in air, gas flow rate $20 \mathrm{~cm}^{3} \mathrm{~min}^{-1}$, residence time $0.3 \mathrm{~s}$, gas hourly space velocity $12000 \mathrm{~h}^{-1}$ and temperature range $25-300{ }^{\circ} \mathrm{C}$. The carrier gas used was oxygen gas. The reaction data were collected after at least $2 \mathrm{~h}$ on-stream at room temperature. The reaction products were determined by gas chromatography-mass spectrometry (GC-MS). The reactant and product mixtures were analyzed using two on-line gas chromatographs equipped with flame ionization and thermal conductivity detectors (FID and TCD, respectively) and an HP-5 column. The catalytic activity was expressed as the degree of conversion of benzene, toluene and $o$-xylene. The conversion of the BTX compounds (equation 1) was calculated as follows:

BTXs $(\%)=\left[(\text { BTXs })_{\text {in }}-(\text { BTXs })_{\text {out }}\right] \times 100 /(\text { BTXs })_{\text {in }}(1)$

where BTXs $(\%)=$ percentage of BTX conversion; $(\mathrm{BTXs})_{\text {in }}=$ input quantity and $(\mathrm{BTXs})_{\text {out }}=$ output quantity.

\section{Results and Discussion}

\section{Catalyst characterization}

The XRD patterns for the materials after calcination are shown Figure 1. The catalysts MS-Ga7\% and MS-Ga11\% showed diffraction bands located at $2 \theta=2.15^{\circ}$, corresponding to (100) reflection, and the absence of (110) and (200) reflections indicates that the insertion of gallium causes a less ordered system which is related to hexagonal array of cylindrical pores. ${ }^{20}$ In addition, the decrease of intensity of XRD peaks may suggest a partial degradation of structure with increase of gallium content. ${ }^{21}$ The main XRD peaks for crystalline gallium oxide are at $2 \theta=30.5,31.7$, $35.2,38.4$ and $64.69^{\circ}$ and for the synthesized materials the XRD bands in the range of $2 \theta=10-80^{\circ}$ do not show diffraction patterns characteristic of crystalline gallium oxide phases present in mesoporous silica. This behavior may indicate that the gallium is tetrahedrally coordinated to oxygen atoms (e.g., silicon) in the framework or is well dispersed and occupies extra framework positions which are not detected by XRD.

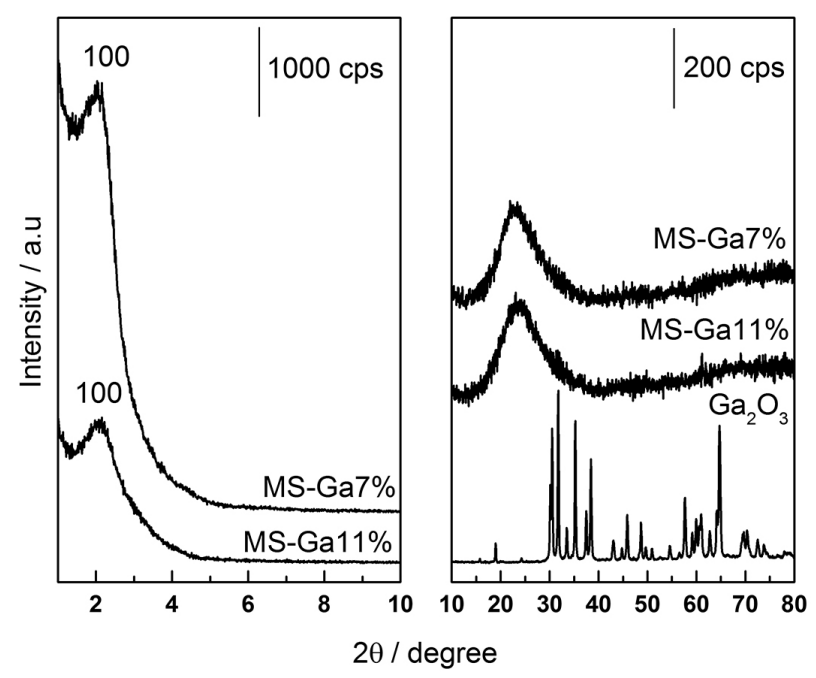

Figure 1. XRD patterns for the MS-Ga7\% and MS-Ga11\% catalysts. 

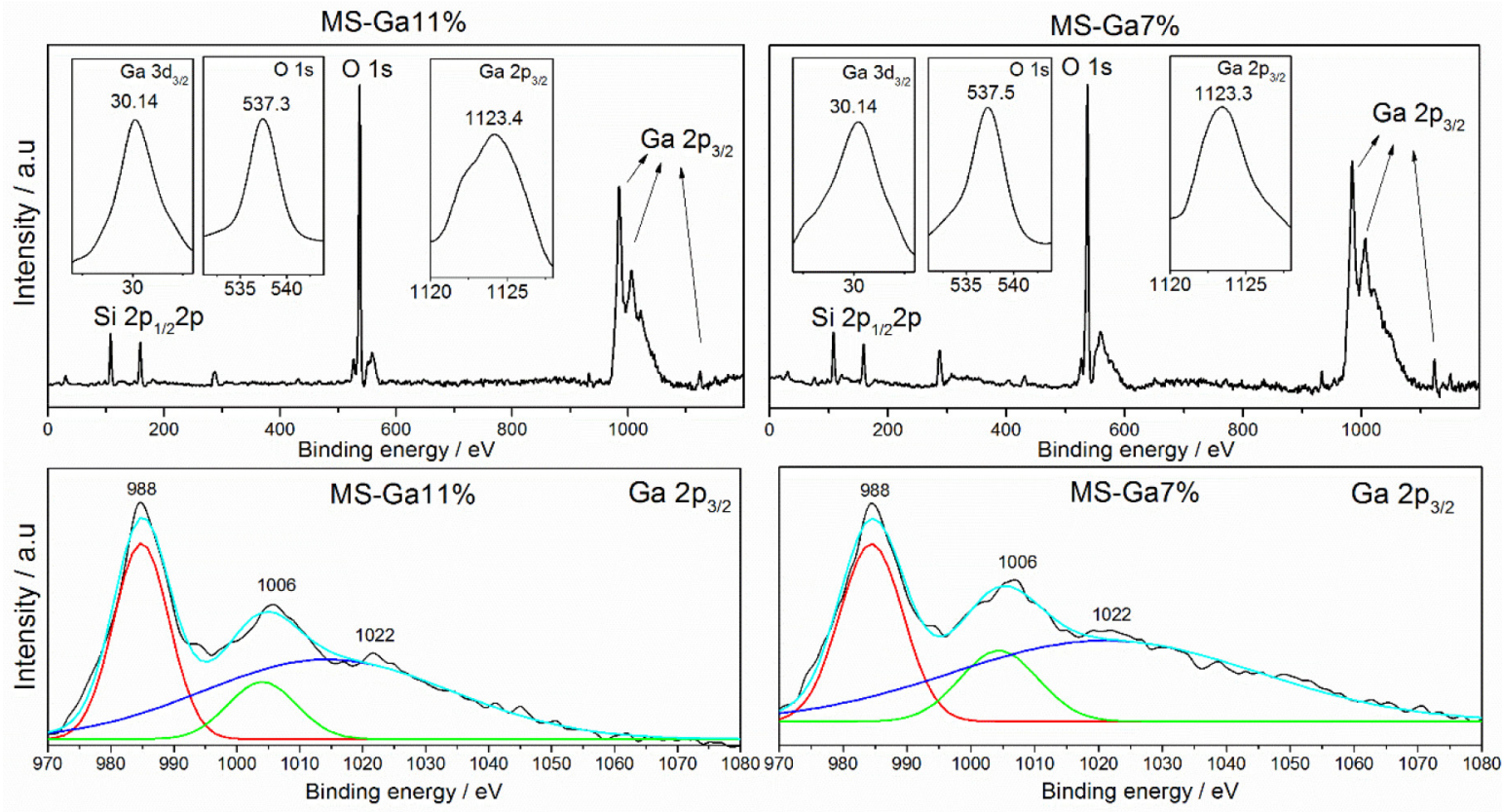

Figure 2. XPS spectra for the MS-Ga7\% and MS-Ga11\% catalysts. Survey spectrum of materials (top line) and high-resolution core-level XPS spectrum of $\mathrm{Ga} 2 \mathrm{p}_{3 / 2}$ regions (bottom line).

In order to examine the oxidation states of gallium in the surface regions of the samples, XPS spectra were obtained (Figure 2 and Table 1). The values for the binding energy of the electrons $\mathrm{O}_{1 \mathrm{~s}}(537.3$ and $537.5 \mathrm{eV})$ were attributed to three types of oxygen species: lattice oxygen in MS-Ga, chemically adsorbed oxygen $\left(\mathrm{O}^{2-}\right)$ in MS-Ga and oxygen associated with the hydroxide $\left(\mathrm{OH}^{-}\right) .{ }^{22}$

The Ga2 $\mathrm{p}_{3 / 2}$ regions can be resolved by two doublets with binding energy values of $\mathrm{Ga} 2 \mathrm{p}_{3 / 2}(988,1006$ and $1123.4 \mathrm{eV}$ ), indicating that the gallium is present in the oxide form $\left(\mathrm{Ga}_{2} \mathrm{O}_{3}\right)$ in the structure. High-resolution core-level XPS spectrum of Ga2 $\mathrm{p}_{3 / 2}$ regions $(988,1006$ and $1022 \mathrm{eV}$ ), as shown in Figure 2 (bottom line), are the most significant regions of the spectrum and are characteristic only of the presence of $\mathrm{Ga}_{2} \mathrm{p}_{3 / 2}$, indicating the presence of the $\mathrm{Ga}_{2} \mathrm{O}_{3}$ phase without the presence of a Ga layer, which confirms that the $\mathrm{Ga}_{2} \mathrm{O}_{3}$ layer is predominantly on the surface of the material. In addition, the presence of the peak $\mathrm{Ga}_{3 / 2}(30.14 \mathrm{eV})$ also verifies the formation of $\mathrm{Ga}_{2} \mathrm{O}_{3}$ on the surface of the sample. This confirms the XRD results, which suggested that the gallium is dispersed on the surface, as metallic gallium and in the oxide form, which may be favorable for complete oxidation to occur on the surface of these materials. ${ }^{23,24}$

XPS analysis of the surface of the catalysts was carried out to determine the percentage of $\mathrm{Ga}_{2} \mathrm{O}_{3}$ on the surface of the catalysts. Interestingly, the catalyst $\mathrm{MS}-\mathrm{Ga} 7 \%$ presented a higher amount of $\mathrm{Ga}_{2} \mathrm{O}_{3}$ on the surface of the material compared to MS-Ga11\%. This will affect the results obtained in the catalytic reactions, since more active sites will be available on the surface of the material, favoring the oxidation reactions. In the case of the catalyst MS-Ga11\%, its low structural order could restrict the availability of the $\mathrm{Ga}$ and $\mathrm{Ga}_{2} \mathrm{O}_{3}$ active centers, which is not favorable to catalytic reactions.

Table 1. Binding energy values and surface composition of the samples determined through XPS analysis

\begin{tabular}{lcccc}
\hline \multirow{2}{*}{ Sample } & \multicolumn{5}{c}{ Binding energy / eV } \\
\cline { 2 - 5 } & $\mathrm{O}_{1 \mathrm{~s}}$ & $\mathrm{Si}_{2} \mathrm{p}_{1 / 2} 2 \mathrm{p}$ & $\mathrm{Ga}_{2} \mathrm{p}_{3 / 2}$ & $\mathrm{Ga3d}_{3 / 2}$ \\
\cline { 2 - 5 } MS-Ga11\% & 537.3 & 108.1 & $988 / 1006 / 1123.4$ & 30.14 \\
MS-Ga7\% & 537.5 & 108.4 & $988 / 1006 / 1123.3$ & 30.14 \\
\hline & \multicolumn{5}{c}{ Composition on the surface of the sample / \% } \\
\cline { 2 - 5 } & $\mathrm{Si}$ & $\mathrm{O}$ & $\mathrm{Ga}$ & $\mathrm{Ga}_{2} \mathrm{O}_{3}$ \\
\hline MS-Ga11\% & 31.98 & 67.57 & 0.235 & 0.220 \\
MS-Ga7\% & 33.85 & 64.52 & 0.635 & 0.987 \\
\hline
\end{tabular}

The results obtained from the oxygen chemisorption measurements are shown in Table 2. The oxygen storage capacity (OSC) for each sample was calculated based on the oxygen uptake. These values allow us to estimate the total amount of oxygen available in the oxide catalyst. The MS-Ga7\% and MS-Ga11\% catalysts presented a high OSC, indicating that these samples have a high amount of oxygen vacancies. The presence of oxygen vacancies enhances the oxygen mobility in the gallium oxide, as also indicated by the characterization results discussed above, favoring high catalytic activity. 
Table 2. Textural properties for catalysts MS-Ga7\% and MS-Ga11\%

\begin{tabular}{lcccccc}
\hline Sample & $\mathrm{d}_{100} / \mathrm{nm}$ & $\mathrm{a}_{0} / \mathrm{nm}$ & $\mathrm{S}_{\mathrm{BET}} /\left(\mathrm{m}^{2} \mathrm{~g}^{-1}\right)$ & $\mathrm{V}_{\mathrm{TP}} /\left(\mathrm{cm}^{3} \mathrm{~g}^{-1}\right)$ & $\mathrm{PSD} / \mathrm{nm}$ & $\left.\mathrm{OSC} /(\mathrm{mmol} \mathrm{m})^{-2}\right)$ \\
\hline MS-Ga7\% & 4.04 & 4.66 & 624 & 0.80 & 3.00 & 12.4 \\
MS-Ga11\% & 4.04 & 4.66 & 520 & 0.60 & 2.90 & 7.6 \\
\hline
\end{tabular}

$\mathrm{d}_{100}=$ interplanar spacing; $\mathrm{a}_{0}=$ hexagonal cell parameter $=2 \mathrm{~d}_{100} / \sqrt{ } 3 ; \mathrm{S}_{\mathrm{BET}}=$ specific area determined by BET equation; $\mathrm{V}_{\mathrm{TP}}=$ pore total volume obtained by $\mathrm{p} / \mathrm{p}^{0}=0.98$ using Gurvich rule; PSD = pore size distribution obtained by desorption values of BJH method; OSC: oxygen storage capacity.

The values for the specific area pore volume and pore diameter of the catalysts are shown in Table 2. It can be observed that an increase in the gallium content causes a decrease in the specific surface area, suggesting a low structural order in the case of MS-Ga11\%. In addition, the pore total volume $\left(\mathrm{V}_{\mathrm{TP}}\right)$ also decreases with an increase in the gallium content.

Both samples provided type IV isotherms typical of a mesoporous structure according to IUPAC (Figure 3 ). ${ }^{25}$ The samples exhibited a high nitrogen adsorption at low relatives pressures $\left(\mathrm{p} / \mathrm{p}^{0}<0.1\right)$ followed by multilayer adsorption at $\mathrm{p} / \mathrm{p}^{0}>0.1$. The inflection region between ranges $\mathrm{p} / \mathrm{p}^{0}=0.25-0.50$ were assigned by filling of mesopores (condensation phenomenon). Moreover, a hysteresis loop was observed at $\mathrm{p} / \mathrm{p}^{0}=0.8-0.98$ which may be related to interparticle mesoporosity. ${ }^{26}$ Furthermore, the inflection of MS-Ga7\% is more pronounced suggesting a pore size distribution more uniform than sample MS-Ga11\%. The Table 2 shows other textural properties which reveals a decrease of specific area and pore volume with increase of gallium content caused by loss of structural ordering as previously observed by XRD.

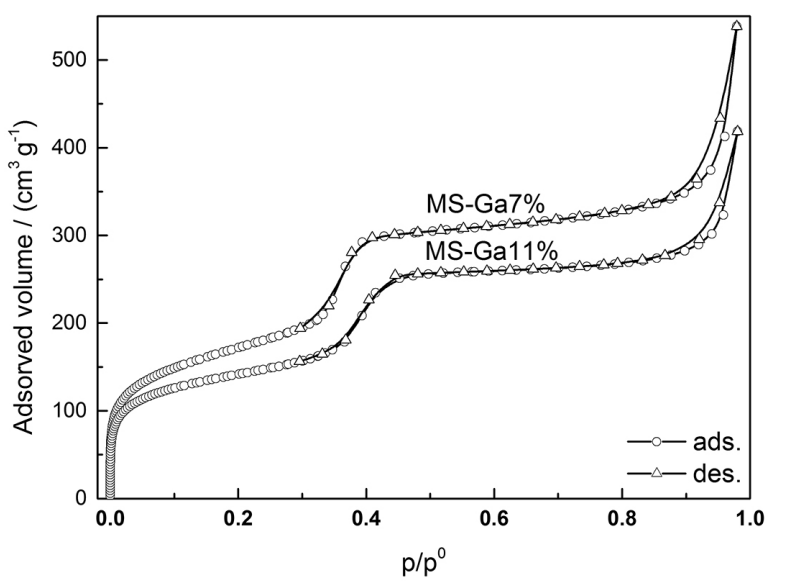

Figure 3. Nitrogen adsorption and desorption isotherms for MS-Ga7\% and MS-Ga11\% catalysts.

The FTIR results for the synthesized materials (Figure 4) showed that the surfactant inside the pores was eliminated for both calcined materials (MS-Ga7\% and MS-Ga11\%), with the absence of symmetric and asymmetric vibration bands 2958, 2921 and $2850 \mathrm{~cm}^{-1}$ related to $\mathrm{C}-\mathrm{H}$ bonds.
Bands are also absent in the region of $1500-1450 \mathrm{~cm}^{-1}$, attributed to the flexing modes of the protonated surfactant $\mathrm{CH}_{3}-\left(\mathrm{N}^{+}\right) .{ }^{27}$ The band at $3500 \mathrm{~cm}^{-1}$ is related to water molecules adsorbed on the surface of the catalysts. The broad bands in the region of $1200-1000 \mathrm{~cm}^{-1}$ can be attributed to internal and external asymmetric vibrations of $\mathrm{Si}-\mathrm{O}$ bonds. ${ }^{28}$ The band at $810 \mathrm{~cm}^{-1}$ is assigned to the symmetric vibration of $\mathrm{Si}-\mathrm{O}-\mathrm{Si}$ bonds, while the signal at $460 \mathrm{~cm}^{-1}$ relates to the deformation of $\mathrm{Si}-\mathrm{O}-\mathrm{Si}$ bonds. ${ }^{21}$

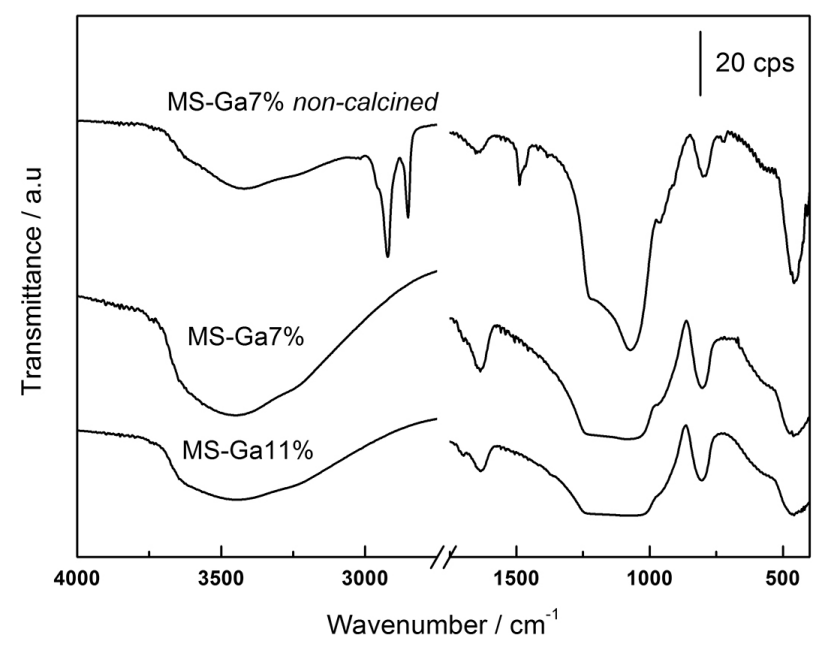

Figure 4. FITR spectra for the MS-Ga7\% and MS-Ga11\% catalysts.

The gallium content in mesoporous silica affects the long-range ordering and structural properties of synthesized materials. Thus, to analyze the morphology and structure in greater depth, SEM and TEM analyses of the catalyst MS-Ga7\% were carried out and the results are shown in Figure 5. In Figure 5a, agglomerated flexed particles with irregular morphology and sizes of approximately $7 \mu \mathrm{m}$ can be observed. The TEM analysis (Figures $5 \mathrm{~b}$ and $5 \mathrm{c}$ ) reveals a sinuous wormhole of pore channels, with short-range order induced by the gallium insertion, in agreement with the XRD results. In addition, an absence of clusters or dense particles of gallium is evident.

\section{Catalyst performance in BTX oxidation}

In order to investigate the catalytic activity of the synthesized catalysts MS-Ga7\% and MS-Ga11\%, benzene, 

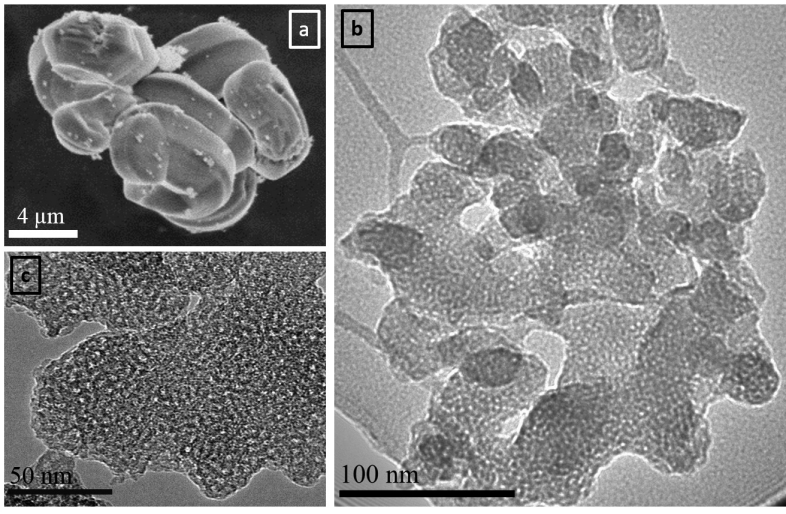

Figure 5. SEM (a) and TEM (b, c) images of the MS-Ga7\% catalyst.

toluene and $o$-xylene (BTX) oxidation reactions were carried out. The only reaction products detected in the experiments were $\mathrm{H}_{2} \mathrm{O}$ and $\mathrm{CO}_{2}$. Figure 6 shows the conversion of $\mathrm{BTX}$ as a function of the reaction temperature for the catalysts studied. It can be observed from these results that the MS-Ga11\% and MS-Ga7\% catalysts were active in the reactions studied and showed a similar tendency, the BTX conversion increasing with an increase in the reaction temperature, as expected.

Catalytic oxidation is greatly influenced by the nature of the reactant. Therefore, different activities can be expected for the different organic compounds under the same reaction conditions. The benzene conversion in the presence of MS-Ga7\% exceeded $72 \%$, the toluene conversion exceeded $48 \%$ and the $o$-xylene conversion exceeded $35 \%$ at $350{ }^{\circ} \mathrm{C}$. The benzene conversion in the presence of MS-Ga11\% exceeded $65 \%$, the toluene conversion exceeded $40 \%$ and the $o$-xylene conversion exceeded $28 \%$ at $350{ }^{\circ} \mathrm{C}$. It has been previously noted that when aromatic compounds are associated with methyl groups they are not easily oxidized as benzene. ${ }^{10,11}$ Blank of the reaction using mesoporous silica MCM-41 (without gallium) did not showed catalytic activity.

The results obtained in the catalyst characterization suggest that the high catalytic activity observed for the MS-Ga7\% and MS-Ga11\% catalysts can be attributed to the presence of gallium oxide on the surface of mesoporous silica, as verified by the XRD and XPS analysis. The MS-Ga7\% catalyst exhibits higher catalytic activity than MS-Ga11\%, which could be related to the fact that MS-Ga7\% has a higher percentage of $\mathrm{Ga}_{2} \mathrm{O}_{3}$ and $\mathrm{Ga}$ on its surface. The presence of $\mathrm{Ga}_{2} \mathrm{O}_{3}$ on the surface means that a greater number of active sites are available, favoring oxidation reactions. ${ }^{29-32}$

It is clear from Table 2 that the conversion was higher for MS-Ga7\% since this catalyst had a higher specific surface area and pore volume. The specific surface area

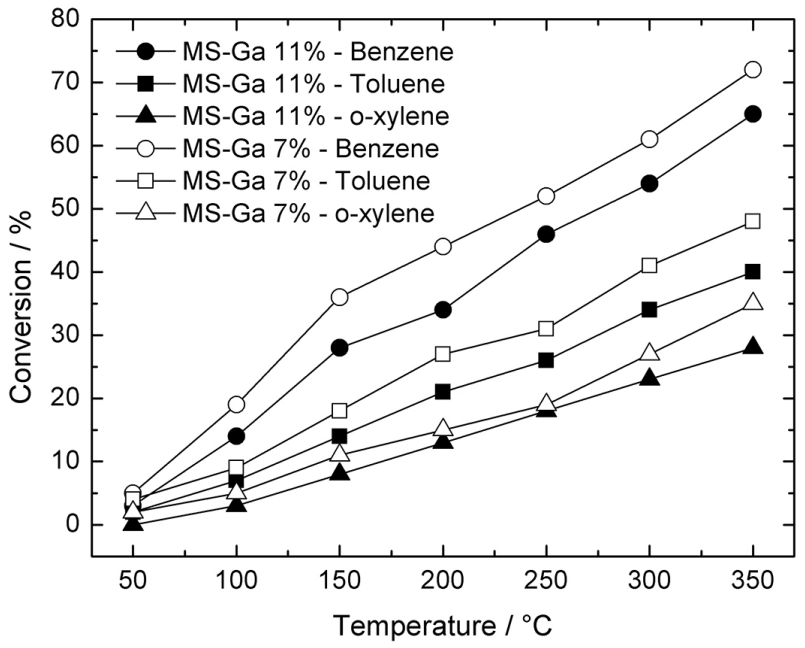

Figure 6. BTX conversion using MS-Ga7\% and MS-Ga11\% catalysts as a function of the reaction temperature.

decreased with an increase in the gallium content, but this did not appear to influence the fact that MS-Ga $11 \%$ showed lower activity. These differences in the activity can be attributed to the physicochemical properties of the catalysts, which varied according to the $\mathrm{Ga}_{2} \mathrm{O}_{3}$ content. Another factor to consider is the presence of oxygen vacancies on the catalyst surface, as confirmed by the characterization results discussed above, which is of importance in relation to the oxidation of hydrocarbons. ${ }^{4,5,13,32,33}$

Thus, the $\mathrm{Ga}_{2} \mathrm{O}_{3}$ may increase the amount of oxygen vacancies and, in turn, the oxygen mobility and the catalytic activity. These vacancies are filled by the oxygen atoms that diffuse from the bulk to the surface of the catalyst, suggesting that the presence of crystalline defects enhances the mobility of the oxygen species, as confirmed by the results for the oxygen storage capacity (OSC). The appearance of oxygen vacancies due to the incorporation of gallium enhanced the oxygen mobility in the catalysts, as also indicated by the OSC results in Table 2. It has been reported that the presence of oxygen vacancies is an important factor influencing the activity of some catalysts and favoring the oxidation process. An increase in the amount of oxygen vacancies can enhance the bulk and surface oxygen mobility, which appears to play an important role in oxidation reactions. Higher oxygen mobility facilitates the migration of oxygen species across the catalyst structure, resulting in greater oxidation activity. This suggests that the reduction in gallium oxide $\left(\mathrm{Ga} / \mathrm{Ga}_{2} \mathrm{O}_{3}\right)$ is not due to the direct release of oxygen into the gas phase, but rather to the interaction which occurs between the surface of the catalyst and the hydrocarbon. These reactions are driven by an increased capacity for the spontaneous release of oxygen from the $\mathrm{Ga} / \mathrm{Ga}_{2} \mathrm{O}_{3}$ system, even in the absence of a reducing agent. In the presence 
of the gallium species, the catalyst promotes the reduction of $\mathrm{Ga}_{2} \mathrm{O}_{3}$, this factor being favorable for the oxidation of hydrocarbons. These characteristics were verified by the XRD, XPS and TEM results.

An increase in the amount of oxygen vacancies could result in an enhancement of the bulk and surface oxygen mobility, which may play an important role in oxidation reactions. It has been previously verified that the introduction of a metal ion can further improve the oxygen mobility by increasing the amount of oxygen vacancies on the catalyst surface. The higher oxygen mobility promotes the migration of oxygen species across the catalyst structure, resulting in higher oxidation activity. Oxygen migration across the catalyst surface is essential in oxidation reactions, where the oxidation-reduction cycles determine the activity of the catalyst. ${ }^{3,6,10,15,30,34-37}$

It is well known that the oxidation of hydrocarbons can proceed via the Mars-van Krevelen mechanism in which the substrate is oxidized by the solid. Thus, the key steps are the supply of oxygen by the reducible oxide, the introduction of the oxygen species of the lattice oxide into the substrate molecule, and the re-oxidation of the reduced solid by the oxygen-containing gaseous phase, which is the rate-determining step of the reaction. Lattice oxygen atoms from the surface of the catalyst are consumed by the organic compound adsorbed on the surface and oxygen vacancies are created. These vacancies are filled by the oxygen atoms that diffuse from the bulk to the surface of the catalyst or by di-oxygen in the air stream during the experiments. In addition, it has been postulated that larger amounts of mobile oxygen species will be encountered on oxides that possess more crystalline defects. In the case of the gallium-doped catalysts, there are more crystalline defects present. Some authors have reported that increasing the oxygen mobility of catalysts, by introducing defective sites, seems to effectively promote hydrocarbon oxidation. These observations may explain the catalytic behavior observed for the MS-Ga catalysts. ${ }^{3,10,11,15}$

\section{Conclusions}

In this study, MS-Ga7\% and MS-Ga11\% catalysts were successfully synthesized and tested for BTX oxidation. The mesoporous materials containing gallium exhibited high catalytic activity in the oxidation of BTX compounds. The characterizations show that gallium doping led to an increase in the oxygen vacancies in the system. In addition, the optical characterization revealed a higher concentration of structural defects and oxygen vacancies on the surface of the MS-Ga7\% catalysts. The catalytic results verify that the reaction conditions and the nature of the catalyst influenced the BTX oxidation. The benzene conversion in the presence of the MS-Ga catalysts exceeded $65 \%$, the toluene conversion exceeded $40 \%$ and the $o$-xylene conversion exceeded $28 \%$ at $350{ }^{\circ} \mathrm{C}$. The performance of the MS-Ga catalyst may be due to a combination of several factors, including high specific area, the number of exposed active sites of gallium and gallium oxide and greater oxygen mobility. Thus, it was verified that the catalyst based on mesoporous silica containing gallium (MS-Ga) described herein is efficient in the conversion of BTX compounds.

\section{Acknowledgments}

The authors are grateful for support provided by UFSC, UFRN and CNPq.

\section{References}

1. Balzer, R.; Probst, L. F. D.; Cantarero, A.; de Lima, M. M.; Araujo, V. D.; Bernardi, M. I. B.; Avansi, W.; Arenal, R.; Fajardo, H. V.; Sci. Adv. Mater. 2015, 7, 1406.

2. da Silva, A. G. M.; Fajardo, H. V.; Balzer, R.; Probst, L. F. D.; Lovon, A. S. P.; Lovon-Quintana, J. J.; Valenca, G. P.; Schreine, W. H.; Robles-Dutenhefner, P. A.; J. Power Sources 2015, 285, 460.

3. Araujo, V. D.; de Lima, M. M.; Cantarero, A.; Bernardi, M. I. B.; Bellido, J. D. A.; Assaf, E. M.; Balzer, R.; Probst, L. F. D.; Fajardo, H. V.; Mater. Chem. Phys. 2013, 142, 677.

4. Hyodo, T.; Hashimoto, T.; Ueda, T.; Nakagoe, O.; Kamada, K.; Sasahara, T.; Tanabe, S.; Shimizu, Y.; Sens. Actuators, B 2015, 220, 1091.

5. Zhong, W. Z.; Kirk, S. R.; Yin, D. L.; Li, Y. Q.; Zou, R.; Mao, L. Q.; Zou, G. Q.; Chem. Eng. J. 2015, 280, 737.

6. da Silva, A. G. M.; Rodrigues, T. S.; Slater, T. J. A.; Lewis, E. A.; Alves, R. S.; Fajardo, H. V.; Balzer, R.; da Silva, A. H. M.; de Freitas, I. C.; Oliveira, D. C.; Assaf, J. M.; Probst, L. F. D.; Haigh, S. J.; Camargo, P. H. C.; ACS Appl. Mater. Interfaces 2015, 7, 25624.

7. Cai, T.; Huang, H.; Deng, W.; Dai, Q. G.; Liu, W.; Wang, X. Y.; Appl. Catal., B 2015, 166, 393.

8. Carabineiro, S. A. C.; Chen, X.; Martynyuk, O.; Bogdanchikova, N.; Avalos-Borja, M.; Pestryakov, A.; Tavares, B.; Orfao, J. J. M.; Pereira, M. F. R.; Figueiredo, J. L.; Catal. Today 2015, 244, 103.

9. Zeng, J. L.; Liu, X. L.; Wan, J.; Lv, H. L.; Zhu, T. Y.; J. Mol. Catal. A: Chem. 2015, 408, 221.

10. Balzer, R.; Drago, V.; Schreiner, W. H.; Probst, L. F. D.; J. Braz. Chem. Soc. 2014, 25, 2026.

11. Balzer, R.; Probst, L. F. D.; Drago, V.; Schreiner, W. H.; Fajardo, H. V.; Braz. J. Chem. Eng. 2014, 31, 757. 
12. Tang, W. X.; Liu, G.; Li, D. Y.; Liu, H. D.; Wu, X. F.; Han, N.; Chen, Y. F.; Sci. China: Chem. 2015, 58, 1359.

13. Jiang, Z.; Chen, M. X.; Shi, J. W.; Yuan, J.; Shangguan, W. F.; Catal. Surv. Asia 2015, 19, 1.

14. Trinh, Q. H.; Lee, S. B.; Mok, Y. S.; J. Hazard. Mater. 2015 , 285, 525.

15. Balzer, R.; Drago, V.; Schreiner, W. H.; Probst, L. F. D.; J. Braz. Chem. Soc. 2013, 24, 1592.

16. Hong, G. B.; Wu, W. S.; Chang, C. T.; Ma, C. M.; J. Chin. Inst. Eng. 2015, 38, 908.

17. Lin, L. Y.; Wang, C. Y.; Bai, H. L.; Chem. Eng. J. 2015, 264, 835.

18. Wu, G.; Gao, Y.; Ma, F. W.; Zheng, B. H.; Liu, L. G.; Sun, H. Y.; Wu, W.; Chem. Eng. J. 2015, 271, 14.

19. Pozzobom, I. E. F.; de Moraes, G. G.; Balzer, R.; Probst, L. F. D.; Triches, E. S.; de Oliveira, A. P. N.; Chem. Eng. Trans. 2015, 43, 1789 .

20. Aprile, C.; Gobechiya, E.; Martens, J. A.; Pescarmona, P. P.; Chem. Commun. 2010, 46, 7712.

21. Bachari, K.; Guerroudj, R. M.; Kinet. Catal. 2012, 53, 395.

22. Zhang, Y. D.; He, W. W.; Zhao, H. X.; Li, P. J.; Vacuum 2013 , 95, 30 .

23. Signoretto, M.; Ghedini, E.; Menegazzo, F.; Cerrato, G.; Crocella, V.; Bianchi, C. L.; Microporous Mesoporous Mater. 2013, 165, 134.

24. di Gregorio, F.; Keller, V.; J. Catal. 2004, 225, 45.

25. Kruk, M.; Jaroniec, M.; Chem. Mater. 2001, 13, 3169.

26. Collard, X.; Li, L.; Lueangchaichaweng, W.; Bertrand, A.; Aprile, C.; Pescarmona, P. P.; Catal. Today 2014, 235, 184.
27. Holmes, S. M.; Zholobenko, V. L.; Thursfield, A.; Plaisted, R. J.; Cundy, C. S.; Dwyer, J.; J. Chem. Soc., Faraday Trans. 1998, 94, 2025.

28. Zholobenko, V. L.; Holmes, S. M.; Cundy, C. S.; Dwyer, J.; Microporous Mater. 1997, 11, 83.

29. Kim, S. C.; Nahm, S. W.; Park, Y. K.; J. Hazard. Mater. 2015 , 300, 104

30. Assebban, M.; El Kasmi, A.; Harti, S.; Chafik, T.; J. Hazard. Mater. 2015, 300, 590.

31. Tang, W. X.; Deng, Y. Z.; Li, W. H.; Li, S. D.; Wu, X. F.; Chen, Y. F.; Catal. Commun. 2015, 72, 165.

32. Huang, H. B.; Huang, W. J.; Xu, Y.; Ye, X. G.; Wu, M. Y.; Shao, Q. M.; Ou, G. C.; Peng, Z. R.; Shi, J. X.; Chen, J. D.; Feng, Q. Y.; Zan, Y. J.; Huang, H. L.; Hu, P.; Catal. Today. 2015, 258, 627.

33. Yuan, G. J.; Zhang, J. B.; Zhang, Y. F.; Yan, Y. A.; Ju, X. X.; Sun, J. M.; Korean J. Chem. Eng. 2015, 32, 436.

34. Hernandez-Morejudo, S.; Masso, A.; Garcia-Gonzalez, E.; Concepcion, P.; Nieto, J. M. L.; Appl. Catal., A 2015, 504, 51.

35. Banu, I.; Manta, C. M.; Bercaru, G.; Bozga, G.; Chem. Eng. Res. Des. 2015, 102, 399.

36. Sinha, S.; Raj, A.; Al Shoaibi, A. S.; Chung, S. H.; J. Phys. Chem. A 2015, 119, 9889.

37. Woo, H. S.; Kwak, C. H.; Chung, J. H.; Lee, J. H.; Sens. Actuators, B 2015, 216, 358.

Submitted: March 2, 2016

Published online: May 6, 2016 